\title{
Review of PPIUCD at tertiary care centre in Southern Rajasthan
}

\author{
Nirmala Sharma ${ }^{1}$, Vinita Gupta ${ }^{2}$, Ashutosh Sharma ${ }^{3}$ \\ ${ }^{1}$ Professor and Head, ${ }^{2}$ Assistant Professor, Department of Obstetrics and Gynaecology, ${ }^{3}$ Associate Professor, \\ Department of Community Medicine, Government Medical College, Kota, Rajasthan, India
}

Background: This study was conducted to observe the acceptance rate and safety for PPIUCD as PPIUCD was used as contraceptive method under family welfare program in this institute. Aims and Objectives: To see pattern of acceptance and safety of PPIUCD among women admitted for childbirth. Materials and Methods: A prospective, preformed semi-structured questionnaire-based observational study was conducted between September 2012 and August 2020 in the Government Medical College Kota. CuT380A was used as PPIUCD for insertion. WHO medical eligibility criteria were met along with inclusion and exclusion criteria. After counseling and consent, PPIUCD was inserted post-placentaly and during LSCS. Acceptance rate was calculated along with safety profile. Results: In the present study majority of patients were in the age group of $21-30$ years. $44.26 \%$ women were second para. $96.35 \%$ insertions were uneventful during the study. The most common reason for acceptance and refusal of PPIUCD was reversibility and for refusal was fear of complications, respectively. The acceptance was increasing over the years. On follow-up majority of clients had no complaints. Among those who had complaints, irregular bleeding was most common. Major cause of requesting for removal was irregular bleeding. Continuation rate was found to be $91.91 \%$ and $85.30 \%$ at 6 weeks and 6 months, respectively. Conclusion: PPIUCD is a safe and effective method of contraception. Acceptance rate is increasing over the years and which can further increase with antenatal, intra natal and postnatal counseling along Access this article online

Website:

http://nepjol.info/index.php/AJMS DOI: 10.3126/ajms.v12i12.39110

E-ISSN: 2091-0576

P-ISSN: 2467-9100

Copyright (c) 2021 Asian Journal of Medical Sciences

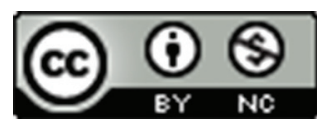

This work is licensed under a Creative Commons Attribution-NonCommercial 4.0 International License. with counseling of husband/family attendants and management of side effects.

Key words: Acceptance; CuT380A; Intra-caesarean insertion; Postpartum insertion;

Postpartum intrauterine contraceptive device; Safety

\section{INTRODUCTION}

According to the 2005-2006 National Family Health Survey, $61 \%$ of births in India were spaced $<3$ years and that $22 \%$ of married women had an unmet need for family planning. ${ }^{1}$ A stratified analysis suggested that $65 \%$ of women in the $1^{\text {st }}$ year postpartum had an unmet need for family planning. ${ }^{2}$ Only $26 \%$ of women are using any method of family planning during the $1^{\text {st }}$ year postpartum. ${ }^{3}$

Over the years with the introduction of IUCD in family welfare program in India awareness and opportunity to get a long-term reversible contraceptive in form of IUCD during postpartum period is increasing day by day to all childbearing women as institutional deliveries also increasing regularly due to introduction of JSY and JSSK.

\section{Aims and objectives}

1. To see pattern in acceptance of PPIUCD among women admitted for childbirth.

2. To assess the safety of PPIUCD.

\section{MATERIALS AND METHODS}

A prospective, preformed semi-structured questionnairebased observational study was conducted between September 2012 and August 2020 in the Department of Obstetrics and Gynaecology, Government Medical College Kota, Rajasthan. 
In family welfare program PPIUCD (CuT380A) was used in this institute. After applying inclusion and exclusion criteria contraceptive counselling was given to all women irrespective of gestational age, maternal age, other risk factors such as parity and proposed mode of delivery presenting in antenatal clinic and to all labor room admissions for delivery. To calculate acceptance, all counseled women admitted for delivery were included in the study. Those who gave written consent for PPIUCD received an intrauterine contraceptive device within $48 \mathrm{~h}$ of placental expulsion in normal deliveries and post placental in caesarean deliveries. All four WHO Medical Eligibility criteria were met in the study. ${ }^{4}$

\section{Inclusion criteria}

All women admitted for childbirth in our institute were counselled for PPIUCD. Consent was obtained from those, who opted for insertion. The following criteria were considered for inclusion in the present study.

1. 18-45-years-old.

2. Desire to have IUCD after counselling.

3. No local infections.

4. $\mathrm{Hb}>10 \mathrm{gm} \%$.

Those women who fulfilled the criteria for insertion were given PPIUCD irrespective of the mode of delivery.

Those women who had either of the following were excluded from the study:

1. Patient with Haemoglobin $<8 \mathrm{~g} / \mathrm{L}$.

2. Un-booked cases handled by Dais.

3. Temperature $>38^{\circ} \mathrm{C}$ or more after labour/ Chorioamnionitis

4. Rupture of membranes $>18 \mathrm{~h}$ prior to labor

5. Un resolved Post-partum haemorrhage

Follow-up was scheduled at 6 weeks and $6^{\text {th }}$ month after insertion.

Each client was asked regarding her experience during the past 6 weeks and 6 months. Their complaints were noted and they were examined regarding thread in situ, infection, evidence of partial expulsion, missing thread etc. USG was done if the thread was not seen and there was no history of expulsion. All cases in which woman gave history of expulsion were also subjected to USG for confirmation.

Those who had complaints such as irregular bleeding and pain abdomen without evidence of infection and IUCD in correct position were given symptomatic treatment and counselled to assure willingness to continue the IUCD. Those who wanted removal on these ground IUCD was removed. Those who had no complaints; and on examination the IUCD was in place were given reassurance and advised to come for the next follow-up.
Those who did not come for scheduled follow up were phoned up. Some of them came late and some were lost to follow up.

Safety was assessed on basis of patient's complaints with respect to excess bleeding, pain abdomen, abnormal discharge if any. Complications such as perforation (if any) were noted. Expulsion rates at 6 weeks and 6 months follow-up were measured.

Software SPSS ver. 16 and Microsoft Excel will be used for statistical analysis.

\section{RESULTS}

In the present study majority ( $85.14 \%$ ) of patients were in the age group of $21-30$ years followed by $10.25 \%$ in $<20$ years age group. Most $(75.23 \%)$ of women included in the study were literate up to 12 classes followed by $14.75 \%$ of illiterate participants. In the present study, $81.96 \%$ of women were Hindu followed by $15.50 \%$ Muslim women (Table 1).

In the present study, $44.26 \%$ of women were second para followed by $31.25 \%$ primiparous women. About $50.83 \%$ insertions were made in post-placental period followed

\begin{tabular}{lc}
\multicolumn{2}{l}{ Table 1: Demographic profile of clients } \\
\hline Demographic character & Insertions $\mathbf{n}(\%)$ \\
\hline Age & \\
$<20$ years & $883(10.25)$ \\
$21-30$ years & $7331(85.14)$ \\
$31-40$ years & $397(4.81)$ \\
Education & \\
Illiterate & $1270(14.75)$ \\
$<12$ th standard & $6478(75.23)$ \\
$>12$ th standard & $863(10.02)$ \\
Religion & \\
Hindu & $7058(81.96)$ \\
Muslim & $1335(15.50)$ \\
Others & $218(2.53)$ \\
\hline
\end{tabular}

\begin{tabular}{|c|c|}
\hline Character & n (\%) \\
\hline \multicolumn{2}{|l|}{ Parity } \\
\hline Primiparous & $2691(31.25)$ \\
\hline Second Para & $3828(44.26)$ \\
\hline Multi parous & $2092(24.29)$ \\
\hline \multicolumn{2}{|l|}{ Time of Insertion } \\
\hline Post-placental & $4377(50.83)$ \\
\hline Post-partum with in 48 hours & 665 (7.72) \\
\hline Intra-caesarean & $3569(41.45)$ \\
\hline \multicolumn{2}{|c|}{ Events in Immediate postpartum period } \\
\hline Uneventful & $8237(96.35)$ \\
\hline Post-partum haemorrhage & $288(3.34)$ \\
\hline Removal of IUCD & $26(0.3)$ \\
\hline Perforation & $00(00)$ \\
\hline
\end{tabular}

Asian Journal of Medical Sciences | Dec 2021 | Vol 12 | Issue 12 
by $41.45 \%$ during LSCS. About $96.35 \%$ insertions were uneventful during the study (Table 2).

Most common (25.95\%) reason for acceptance of PPIUCD was reversibility of method followed by long term use of IUCD $(23.93 \%)$.

Major reason (31\%) for refusal was fear of complications followed by husband/family refusal (25.99\%) (Table 3).

After applying inclusion and exclusion criteria out of 124234 deliveries in study duration only 44606 women could get counselled about PPIUCD. From these counseled women 8611 women accepted PPIUCD so cumulative acceptance rate among counseled women was $19.30 \%$ (Table 4).

As awareness and information and antenatal counselling were increasing on PPIUCD the acceptance was also increasing for PPIUCD as it was $9.10 \%$ of total counselled deliveries in 2012 and raised to $34.68 \%$ in 2020 (Table 5).

\begin{tabular}{lc}
\multicolumn{2}{l}{ Table 3: Reason for acceptance and refusal } \\
\hline Reason & $\mathbf{n}(\%)$ \\
\hline Reason for acceptance & \\
Reversible & $2242(25.95)$ \\
Long term & $2061(23.93)$ \\
No remembrance once inserted & $1639(19.01)$ \\
Fewer clinic visit & $1376(15.98)$ \\
Safe & $602(6.99)$ \\
Faith on doctor & $517(6.00)$ \\
No interference with breastfeeding & $174(2.02)$ \\
Reason for refusal & $11159(31)$ \\
Fear of complications & $9351(25.99)$ \\
Husband/family Refusal & $6119(6.99)$ \\
Prefer other contraceptive method & $2521(7.00)$ \\
Wants permanent method & $1820(5.05)$ \\
Myth that she does not want any & \\
contraceptive method & \\
\hline
\end{tabular}

\begin{tabular}{lc} 
Table 4: Acceptance of PPIUCD \\
\hline Total number of counselled \\
Accepted & 44606 \\
Refusal & $8611(19.30)$ \\
\hline
\end{tabular}

On follow up at 6 weeks and 6 months majority $(86.11 \%$ and $87.68 \%$ ) of clients were having no complaints. Among those who had complaints, irregular bleeding was most common $(5.64 \%$ and $3.07 \%)$ followed by pain abdomen $(3.50 \%$ and $2.45 \%)$.

Study had $2.00 \%$ and $1.22 \%$ of clients as lost to follow-up at 6 weeks and 6 months, respectively. So at 6 weeks, 173 were lost to follow-up and 523 removal were excluded from the further part of the study (Table 6).

About $92.86 \%$ and $92.44 \%$ of clients had their thread in situ on examination at 6 weeks and 6 months, respectively. Only $3.24 \%$ and $2.47 \%$ clients had missing thread on examination during follow up at 6 weeks and 6 months, respectively.

About $06.19 \%$ and $5.84 \%$ clients requested removal on follow up at 6 weeks and 6 months, respectively. Major cause of requesting for removal was irregular bleeding in $39.57 \%$ and $26.78 \%$ followed by pain abdomen in $17.01 \%$ and $14.25 \%$ during follow-up at 6 weeks and 6 months, respectively (Table 7 ).

The study found continuation rate of $91.91 \%$ and $85.30 \%$ at 6 weeks and 6 months, respectively along with zero perforation (Table 8 ).

\section{DISCUSSION}

Present study found that majority of acceptors were in the age group of $21-30$ years which is in accordance to various prior studies. ${ }^{5-8}$

Most $(75.23 \%)$ of women participated in the present study were literate up to $12^{\text {th }}$ standard while study done by Jain and Bindal, ${ }^{5}$ Gnanasekar ${ }^{7}$ and Gonie et al., ${ }^{8}$ found that majority of acceptors had primary level, graduate level and secondary level of education, respectively.

In the present study, $81.96 \%$ of women were Hindu followed by $15.50 \%$ Muslim women. In the present study,

\begin{tabular}{|c|c|c|c|c|c|c|c|}
\hline Year & $\begin{array}{c}\text { Total } \\
\text { Deliveries }\end{array}$ & $\begin{array}{c}\text { Total Counselled } \\
(\%)\end{array}$ & $\begin{array}{c}\text { Counselled in } \\
\text { ND (\%) }\end{array}$ & $\begin{array}{l}\text { Counselled in } \\
\text { LSCS (\%) }\end{array}$ & $\begin{array}{l}\text { Insertions in } \\
\text { ND (\%) }\end{array}$ & $\begin{array}{l}\text { Insertions in } \\
\text { LSCS (\%) }\end{array}$ & Total Insertions (\%) \\
\hline 2013 & 11805 & $2056(17.41)$ & 1212 (58.94) & $844(41.06)$ & 199 (16.41) & 143 (16.94) & 342 (16.63) \\
\hline 2014 & 13128 & $4002(30.48)$ & $2818(70.14)$ & $1184(29.56)$ & $217(7.70)$ & $195(16.46)$ & 412 (10.29) \\
\hline 2015 & 14642 & 4786 (32.68) & 3315 (69.26) & $1471(30.74)$ & 321 (9.68) & 332 (22.56) & $653(13.64)$ \\
\hline 2016 & 15850 & 5402 (34.08) & 3856 (71.38) & $1546(28.62)$ & 409 (10.60) & 521 (33.69) & 930 (17.21) \\
\hline 2017 & 16327 & $6232(38.16)$ & $4123(66.15)$ & 2109 (33.85) & 455 (11.03) & 499 (23.66) & $1054(16.91)$ \\
\hline 2018 & 15770 & 7296 (46.26) & 4945 (67.77) & 2351 (31.72) & 440 (8.89) & $696(29.60)$ & $1136(15.57)$ \\
\hline 2019 & 15565 & 7967 (51.18) & $5452(68.43)$ & 2515 (31.57) & $1286(23.58)$ & 952 (37.85) & 2238 (28.09) \\
\hline 2020 & 10818 & 4867 (44.98) & 3125 (64.20) & $1742(35.80)$ & 656 (20.99) & $1008(57.86)$ & 1664 (34.18) \\
\hline
\end{tabular}


Table 6: Follow up complaints and lost to follow up

\begin{tabular}{lcc}
\hline Follow up complaints & $\mathbf{6}^{\text {th }}$ week & $\mathbf{6}^{\text {th }}$ month \\
\hline No complaints & $7266(86.11)$ & $6940(87.68)$ \\
Irregular Bleeding & $476(5.64)$ & $243(3.07)$ \\
Pain Abdomen & $296(3.50)$ & $194(2.45)$ \\
White Discahrge & $53(0.62)$ & $35(0.44)$ \\
Expulsion & $26(0.30)$ & $13(0.16)$ \\
Others & $125(1.48)$ & $97(1.22)$ \\
Lost to follow up & $173(2.00)$ & $106(1.33)$ \\
\hline
\end{tabular}

Table 7: Finding and removal of iucd on follow up and cause of removal

\begin{tabular}{lcc}
\hline $\begin{array}{l}\text { Finding on follow up } \\
\text { and cause of removal }\end{array}$ & $\mathbf{6}^{\text {th }}$ week & $\mathbf{6}^{\text {th }}$ month \\
\hline $\begin{array}{l}\text { Finding on follow-up } \\
\text { examination }\end{array}$ & \\
$\quad$ Thread in situ & $7836(92.86)$ & $7317(92.44)$ \\
Partial expulsion & $132(1.56)$ & $9(0.11)$ \\
Missing string & $274(3.24)$ & $196(2.47)$ \\
Removal of IUCD & $523(6.19)$ & $463(5.84)$ \\
Cause of removal & & \\
Irregular bleeding & $207(39.57)$ & $124(26.78)$ \\
Pain abdomen & $89(17.01)$ & $66(14.25)$ \\
Partial expulsion & $132(25.23)$ & $9(1.94)$ \\
Social & $67(12.81)$ & $39(8.42)$ \\
Others & $28(5.35)$ & $35(7.55)$ \\
\hline
\end{tabular}

\begin{tabular}{lcc}
\multicolumn{4}{l}{ Table 8: Continuation Rate for PPIUCD } \\
\hline Continuation rate & $\mathbf{6}^{\text {th }}$ week & $\mathbf{6}^{\text {th }}$ month \\
\hline Continuation rate & $7915(91.91)$ & $7346(85.30)$ \\
\hline
\end{tabular}

$44.26 \%$ of women were second para which was similar to study conducted by Gonie et al., ${ }^{8}$ Studies conducted by Jain and Bindal, ${ }^{5}$ Madhuri and Sreelakshmi ${ }^{6}$ and Gnanasekar ${ }^{7}$ had more primiparous as most common acceptor.

In this study $50.83 \%$ insertions were made in post-placental period followed by $41.45 \%$ during LSCS which is similar to another study conducted by Ranjana et al.," which had $52.94 \%$ post-placental $42.64 \%$ intra caesarean and $4.41 \%$ post-partum insertion. While in study by Vilvapriya and Veeraragavan ${ }^{10} 78.3 \%$ of insertions were intra Caesarean $14 \%$ post-placental and $7.7 \%$ were postpartum.

About $96.35 \%$ insertions were uneventful during the study which was similar to study done by Agarwal and Singh. ${ }^{11}$

The present study revealed that the most common $(25.95 \%)$ reason for acceptance of PPIUCD was reversibility of this method while study conducted by Jain and Bindal et al., ${ }^{5}$ and Gnanasekar ${ }^{7}$ found non-hormonal property and non-interference to breastfeeding property of PPIUCD as most common reason for acceptance respectively. In a study done by Barala et al. ${ }^{12}$ long life of PPIUCD was most common reason for choosing this method of contraception.
This study found fear of complications as major reason (31\%) for refusal of PPIUCD which was similar to study done by Jain and Bindal et al., ${ }^{5}$ and Gnanasekar ${ }^{7}$ while Barala et al., ${ }^{12}$ revealed the use of another method of contraception as common cause of refusal of this method.

This study found cumulative acceptance rate of 19.30\% which is comparable to Gnanasekar ${ }^{7}$, Gonie et al., ${ }^{8}$ and Barala et al. ${ }^{12}$

The present study found that during the study period the acceptance rate was continuously increasing year wise. This may be due to raising level of awareness knowledge and regular antenatal counselling for contraception. No other study calculated yearly acceptance rate so far.

In our study on follow-up at 6 weeks and 6 months majority of clients were having no complaints. This is comparable to study findings of Agarwal and Singh ${ }^{11}$ and Chauhan et al., ${ }^{13}$ while Jain et al., ${ }^{14}$ found clients without complaints were only $24.75 \%$ and $19.25 \%$.

Among those who had complaints, irregular bleeding and pain abdomen were most common. This finding was similar to previous studies. ${ }^{5,6,11,15}$

The study had $1.48 \%$ and $1.22 \%$ of clients as lost to follow-up at 6 weeks and 6 months respectively which is less than other studies. ${ }^{7,16}$

More than $90 \%$ of clients had their thread in situ on examination on follow up which is comparable to finding of Gnanasekar ${ }^{7}$ and Agarwal and Singh. ${ }^{11}$

This study revealed that $3.24 \%$ and $2.47 \%$ of clients had missing thread on examination on follow up which is similar to the study conducted by Pandher et al., ${ }^{15}$ while other studies had more missing threads present study. ${ }^{6,711}$

About $6 \%$ of clients requested IUCD removal on follow up which was less than study done by Gnanasekar ${ }^{7}$, Ranjana et al., ${ }^{9}$ and Rani et al. ${ }^{17}$

Major causes of requesting for removal were irregular bleeding and pain abdomen on follow up which were similar to studies done by Madhuri and Sreelakshmi ${ }^{6}$, Gnanasekar ${ }^{7}$ and Ranjana et al. ${ }^{9}$

Study found continuation rate of $91.91 \%$ and $85.30 \%$ on follow-up which is comparable to findings revealed in studies done by Madhuri and Sreelakshmi ${ }^{6}$ and Pandher et al. ${ }^{15}$ 
Limitations of the study

Number of counselors were inadequate during initial part of study period and Lost to follow up clients could not be traced because of limited resources.

\section{CONCLUSION}

PPIUCD is safe and effective method of contraception. Over the years acceptance rate for PPIUCD was increased which can further increase with antenatal, intra natal and postnatal counselling along with counselling of husband/ family attendants and management of side effects acceptance rate can be improved. In developing countries where postnatal services including contraception are not frequently utilised by mothers/families, it can be an effective tool to slow down population growth.

\section{ACKNOWLEDGMENT}

Authors acknowledge all participants of study and counselors, faculty members and residents of department of obstetrics and gynecology govt. medical college kota.

\section{REFERENCES}

1. International Institute for Population Sciences (IIPS) and Macro International: National Family Health Survey (NFHS-3), 200506, India, Key Findings. Mumbai, IIPS; 2007. Available from: http://www.measuredhs.com/pubs/pdf/SR128/SR128.pdf [Last accessed on 2013 Mar 14].

2. Borda M. Family Planning Needs during the Extended Postpartum Period in India. Access Family Planning Initiative Brief, 2009. Available from: http://www.accesstohealth.org/ toolres/pdfs/india_an alysis.pdf [Last accessed on 2013 Mar 14].

3. Post-Partum IUCD Reference Manual; Family Planning Division. Ministry of Health and Family Welfare. Vol. 1. Government of India; 2010. p. 2.

4. Medical Eligibility Criteria for Contraceptive Use. $5^{\text {th }}$ ed. 2015. Available from: http://apps.who.int/iris/ bitstream/10665/181468/1/9789241549158_eng.pdf. [Last accessed on $2021 \mathrm{Jul} 13$ ].

5. Jain R and Bindal J. Evaluation of post-placental and intracesarean insertion of copper-t 380a as a method of contraception. J Med Sci Clin Res. 2018;6(6):871-877. https://dx.doi.org/10.18535/jmscr/v6i6.146

6. Madhuri $\mathrm{C}$ and Sreelakshmi G. Evaluation of the acceptance, efficacy and safety of postpartum intrauterine contraceptive device and the complications associated with it. Int $\mathrm{J}$ Curr Med Appl Sci. 2017;16(3):132-136.

7. Gnanasekar I. Evaluation of Acceptance, Safety, and Expulsion of Postplacental Intrauterine Contraceptive Devices 10.5005/jpjournals-10006-1572.

8. Gonie A, Worku C, Assefa T, Bogale D and Girma A. Acceptability and factors associated with post-partum IUCD use among women who gave birth at bale zone health facilities, SoutheastEthiopia. Contracept Reprod Med. 2018;3:16. http://doi.org/10.1186/s40834-018-0071-z

9. Ranjana, Verma A and Chawla I. A follow up study of postpartum intrauterine device insertion in a tertiary health care centre. Int J Reprod Contracept Obstet Gynecol. 2017;6(7):2800-2805.

10. Vilvapriya $S$ and Veeraragavan K. Long term clinical outcome of post-partum intra uterine contraceptive device (PPIUCD) insertion. Int J Cur Res Rev. 2016;8(11):28-33.

11. Agarwal R and Singh $S$. Evaluation of Safety and efficacy of postpartum intrauterine contraceptive devices (PPIUCD) in vaginal and caesarean section deliveries: A hospital based study. MAMC J Med Sci. 2020;6(3):199-203.

http://doi.org/10.4103/mamcjms.mamcjms_53_20

12. Barala S, Maheshwari S, Sharma P. Analysis of awareness, acceptance, safety and continuation rate of postplacental and intra-caesarean insertion of intrauterine contraceptive device. Int J Reprod Contracept Obstet Gynecol. 2016;5(6):1974-1980. http://dx.doi.org/10.18203/2320-1770.ijrcog20161701

13. Chauhan R, Sahni $S$ and Hanumantaiya $S$. Evaluation of acceptability, safety and expulsion rate of PPIUCD. Int J Reprod Contracept Obstet Gynecol. 2018;7(3):1083-1089. http://dx.doi.org/10.18203/2320-1770.jjrcog20180897

14. Jain S, Priyadarshini P and Konar H. Evaluation of acceptability, safety, and efficacy of intrauterine device insertion during the postpartum period: A prospective analysis. Int J Sci Stud. 2019;7(5):70-75.

15. Pandher DK, Rani S and Goel P. Two years follow up study of post placental insertion of IUCD during caesarean sections: Safety, efficacy and complications. Int J Reprod Contracept Obstet Gynecol. 2018;7(3):981-986. http://dx.doi.org/10.18203/2320-1770.jjrcog20180877

16. Paul DP, Ray J and Sarkar S. Study of outcome of Intrauterine Contraceptive device (CuT-380A) insertion immediately after vaginal delivery. AIMS Med Sci. 7(4):328-336. http://doi.org/10.3934/medsci.2020022

17. Rani M, Kaur P, Kaur K, Kaur G, Kaur SP. A study to evaluate safety and efficacy of postpartum intrauterine contraceptive device insertion. Indian J Clin Pract. 2019;30(1):40-43.

\footnotetext{
Authors Contribution:

NS- Concept and design of the study; VG- Concept, coordination prepared first draft of manuscript; AS- Concept and design of the study, statistical analysis and interpretation, preparation of manuscript and revision of the manuscript

Work attributed to:

Government Medical College, Kota - 324 005, Rajasthan, India

Orcid ID:

Dr. Nirmala Sharma - (i) https://orcid.org/0000-0001-8750-8218

Dr. Vinita Gupta - (D) https://orcid.org/0000-0002-4960-1371

Dr. Ashutosh Sharma - (D) https://orcid.org/0000-0003-3131-1410

Source of Funding: None, Conflicts of Interest: None.
} 